AFTER two months of "such limited studies as he was able to make", Sir James Lighthill (Artificial Intelligence, SRC, April 1973) has rejected the claim of artificial intelligence to special consideration by the Science Research Council on grounds which differ remarkably little from Lady Lovelace's objection to Babbage's analytical machine in 1842 (Turing, Mind, 59, 433; 1950). Apparently it is as true today as it was more than a century ago that what you get out of a machine depends on what you put into it: as Lady Lovelace has it, "The Analytical Engine has no pretensions to originate anything. It can do whatever we know how to order it to perform"; or according to Lighthill, modern machines can successfully “. . . perform in highly specialized problem domains, when the programming takes very full account of human experience and human intelligence within the relevant domain ....".

He goes on, however, to describe as the "coveted longterm goal of AI" the development of "a general-purpose program secking to mimic the problem-solving aspects of human CNS activity". It is on the grounds of what he feels to be inadequate progress towards this goal that Lighthill concludes that further support for basic research on artificial intelligence as such-that is, as distinct from advanced automation or theoretical neurobiology-is unjustified. This immediately exposes him to the criticism that mimicking human intelligence is not the goal of artificial intelligence research, which is concerned with intelligence per se, and not necessarily as implemented in the human brain.

Be that as it may, it is entirely understandable that an outsider should come away with the impression that mimicry is the ultimate aim, when according to many insiders the crowning achievement in the field so far is Winograd's program for conversing with a machine in natural language (see Nature, 242, 372; 1973; and Winograd, Understanding Natural Language, Edinburgh University Press, 1972). The excitement engendered by this development is acknowledged by Lighthill in a postscript considering separately the claim made for the program as vindicating artificial intelligence research.

The success of Winograd's program in dealing with the complexities inherent in the ordinary use of English depends partly on its having access to information on the universe of discourse: its behaviour is guided by the context within which it is working, as would be the case with human behaviour, and not simply by the input and its own intrinsic logic. In spite of this gift of human nous, Lighthill points out, it took a large computer a long time to make simple conversation about coloured blocks on a table top; and Lady Lovelace's objection still stands.

Thus Lighthill concludes that the results of work on artificial intelligence remain disappointing, and adds, more contentiously, that its goals are as remote as ever: a guess which is presumably based on Lighthill's general impression of the quality of work in the field. Professor N. S. Sutherland, in a cogent if somewhat waspish critique of Lighthill, raises the possibility that his impres- sion is a function of the singers rather than the song. Sutherland bluntly states, "There is little first class work on basic AI in progress in Britain at the moment"; the leading workers in the field are mostly in the United States at Stanford or the Massachusetts Institute of Technology, and according to Professor D. M. Michie, who also submitted his comments, Lighthill did not actually speak to them.

Sutherland argues vehemently the importance of studying intelligence without the constraints of its mechanism in living brains (which, he points out, can generate some extremely unintelligent behaviour). In concrete terms, artificial intelligence research has produced some extremely sophisticated programming techniques which Sutherland believes have general application. Lighthill does not dispute the contribution of $\mathrm{AI}$ research to the understanding of natural language; on the same principle, Sutherland emphasizes the insight into the processes of thought and perception gained by the attempt to formalize them.

As far as Sutherland is concerned, the source of most that is good is the group at MIT headed by Marvin Minsky and Seymour Pappert, within which the ideas and techniques on which Winograd's program is based were developed. This view is reflected strongly in his suggestions for the deployment of research funds. These include importing young workers from the United States, the provision of computers which can accept US software, and sending young Britons for training to MIT. One role which Sutherland envisages for basic AI centres is in the training of young workers to supply the other related research areas of advanced automation and theoretical investigation of the central nervous system.

It is fair to say that progress in artificial intelligence has been unamazing; but in the twenty or so years that have elapsed since Turing considered the question of whether machines could think, and concluded with the suggestion that a machine might be built to play chess, or to understand English, machines have been developed that play chess, albeit only at the level of the talented amateur; and now they can also speak English, if only with the voice of the programmer. Progress in the next twenty years will doubtless depend on financial support for workers of Turing's calibre.

\section{Probing in the Rain}

THE increasing demand for telecommunications capacity in Earth-satellite and terrestrial networks requires the extension of present services to carrier frequencies above $10 \mathrm{GHz}$. Not only do new channels then become available but practical bandwidths are compatible with the needs of high-speed transmission of digital information.

An important problem in the development of the new services is the attenuation of the signals with absorption and scattering of energy which occurs due to precipitation in the transmission path. Rain, for instance, is 